\title{
Immunogenicity when utilizing adenovirus serotype 4 and 5 vaccines expressing circumsporozoite protein in naïve and Adenovirus (Ad5) immune mice
}

Nathaniel J Schuldt', Yasser A Aldhamen ${ }^{3}$, Sarah Godbehere-Roosa ${ }^{3}$, Sergey S Seregin ${ }^{3}$, Youssef A Kousa ${ }^{4}$ and Andrea Amalfitano ${ }^{1,2,3,4^{*}}$

\begin{abstract}
Background: Induction of potent long lasting effector T cell responses against liver stage malaria antigens strongly correlates with protection from malaria. While Adenovirus serotype 5 (Ad5) based malaria vaccine platforms have the ability to induce potent effector $T$ cell responses against transgenes, high rates of pre-existing Ad5 immunity in malaria endemic regions has prompted study of alternative Ad serotype based malaria vaccines as replacements for Ad5 based malaria vaccines. The research described in this article examines the utility of alternative serotype adenovirus serotype 4 (Ad4) expressing a sporozoite surface protein (circumsporozoite protein (CSP)) (Ad4-CSP) to induce immune responses against CSP. The immunogenicity of Ad4-CSP was also tested in homologous and heterologous prime boost vaccinations in both Ad5 naïve and Ad5 immune backgrounds as compared to use of Ad5-CSP.

Results: In Ad5 naïve animals, use of Ad4-CSP priming vaccinations followed by boosting with Ad5-CSP (Ad4-CSP/ Ad5-CSP) maximally increased the numbers of CSP specific cytokine secreting cytotoxic $T$ cells relative to repeated use of Ad5-CSP. The Ad4-CSP/Ad5-CSP regimen also induced equivalent levels of CSP specific cell killing as did homologous prime-boost vaccinations with Ad5-CSP, despite stimulating lower numbers of CSP specific cytotoxic T cells. Priming with Ad4-CSP followed by a homologous boost resulted in significantly less CSP specific humoral responses than any other vaccination regimen tested in Ad naïve animals. In Ad5 immune animals, addition of Ad4-CSP in homologous or heterologous prime boost resulted in inductions of higher CSP specific responses than animals repeatedly vaccinated with Ad5-CSP alone. However, the observed responses were well below those observed in similarly treated Ad naïve mice.

(Continued on next page)
\end{abstract}

\footnotetext{
* Correspondence: amalfit1@msu.edu

'Genetics Program, Michigan State University, 2240 E Biomedical and

Physical Sciences Building, East Lansing, Ml 48824, USA

${ }^{2}$ Department of Pediatrics, Michigan State University, East Fee Hall, East

Lansing, Ml 48824, USA

Full list of author information is available at the end of the article
} 
(Continued from previous page)

Conclusions: While the Ad4-CSP/Ad5-CSP and Ad5-CSP/Ad5-CSP vaccination regimens resulted in equivalent CSP specific killing in Ad naïve animals, Ad4-CSP/Ad5-CSP achieved this result with a lower percentage of CSP specific $\mathrm{CD}^{+} \mathrm{T}$ cells and a higher number of IFNy secreting cells, suggesting that the Ad4-CSP/Ad5-CSP vaccination regimen elicits more efficient cytotoxic T cells. In Ad5 immune animals use of Ad4-CSP improved CSP specific immune responses as compared to repeated use of Ad5-CSP, but could not achieve the levels of immunogenicity observed when the same vaccine regimens were used in Ad naïve animals. These data indicate the existence of some level of immunological cross-reactivity between these two adenovirus subgroups. Based on these results, it is suggested that future studies should undertake similarly stringent analyses of alternative Ad serotypes to establish their effectiveness as replacements for Ad5.

Keywords: Serotype 5, Serotype 4, Adenovirus, Malaria, Circumsporozoite protein, Vaccine, Heterologous, Homologous, Prime, Boost

\section{Background}

Despite use of prophylactic medications and vector control, malaria continues to be one of the world's most deadly health concerns claiming the lives of almost 1 million people annually. The protozoan parasite, Plasmodium falciparum, accounts for about 90\% of these deaths [1]. Numerous $P$. falciparum targeted vaccine studies are currently underway in efforts to eliminate this dangerous killer. The $P$. falciparum derived circumsporozoite protein (CSP) is the most studied and commonly used antigen for the purpose of developing a vaccine against malaria [2-6]. CSP is abundant on the surface of the sporozoite, and is also present in the plasma membrane and cytosol of plasmodium infected hepatocytes. CSP is a $58 \mathrm{kD}$ protein composed of a C-terminus containing the thrombospondin-like type I repeat region (TSR involved in liver sinusoid attachment), a central region of [NANP] repeats, and a $\mathrm{N}$-terminal site that when in contact with the liver sinusoid is cleaved exposing the TSR [7-9].

Of the several malaria vaccine vectors that target CSP, the most successful to date is a vaccine formulation that consists of a novel fusion protein between the hepatitis B surface protein (HBsAg) and CSP, and additional adjuvants. This formulation, referred to as RTS,S/AS01B, is currently in a phase 3 clinical trial [10]. This vaccine has been able to confer protection to $56 \%$ of vaccinated individuals [3,10-15]. Although promising, the results also suggest that more potent immune responses may be required to achieve higher levels of protection. For this reason other vectors and immunogenic strategies incorporating CSP are being pursued in efforts to develop a highly efficacious, malaria specific vaccine.

Recombinant adenovirus serotype 5 (rAd5) based vaccines are important in this regard as they have been confirmed to elicit potent adaptive responses against expressed transgenes [16-18]. Multiple studies have utilized rAd5s genetically engineered to express CSP in human and mouse models of malaria $[6,19,20]$. However, pre-existing Ad5 immunity is common in regions where malaria is endemic, and the presence of neutralizing antibodies against Ad5 has been shown to hinder Ad5 based vaccine efficacy [21-23]. It has been hypothesized that the use of alternative serotype based rAds may induce improved immunogenic responses to antigens irrespective of pre-existing Ad5 immunity, for example in HIV vaccine development [24,25]. There are at least 52 different human Adenovirus serotypes. Adenovirus serotypes are divided into subgroups A-F based primarily on anti-sera neutralization. Since Ad5 is a member of subgroup $C$, it is hypothesized that alternative serotypes from other subgroups would not be neutralized by Ad5 antibody and therefore, could still be utilized to infect cells and stimulate immunity to an expressed transgene. Use of alternative serotype based Ad vectors can serve other important purposes aside from stimulating immune responses in Ad5 immune patients. Heterologous prime boost regimens where the prime and boost vaccinations are derived from two different Ad serotypes based vaccines can provide greater inductions of immunity than homologous prime boosting with a single Ad serotype based vaccine [26-28].

In this context, Ad4 based vectors may be promising for use in malaria specific applications. The efficacy and safety of Ad4 vaccine platforms has been established. For instance, as the principal serotype causing Acute Respiratory Disease (ARD) in military recruits, an orally administered, live Ad4 virus was utilized for decades in vaccinations of recruits against ARD [29-32]. More recently, Ad4 based vaccines have been successfully utilized in HIV vaccine strategies in dog and chimpanzee models [24,25]. This research article analyses the ability of an Ad4-based malaria specific vaccine expressing CSP to stimulate potent immune responses when used in 
homologous or heterologus prime boost regimens with an Ad5 vaccine also expressing CSP, both in the context of Ad5 naïve and Ad5 immune animals.

\section{Methods}

\section{Vector construction}

The open reading frame (ORF) of the $P$. falciparum CSP gene, composed of a codon optimized consensus of several P. falciparum CSP sequences, was incorporated into an E1, E3 deleted adenovirus serotype 5 vector under the control of a cytomegalovirus (CMV) enhancer/promoter element as previously described [33]. The same CSP consensus sequence was incorporated into an E1, E3 deleted adenovirus serotype 4 vector under the expressional control of the same CMV enhancer/promoter element. Ad4 vector construction was performed as previously described with an Ad4 recombination based production system [34].

\section{Animal procedures}

All animal procedures were approved by the Michigan State University Institutional Animal Care and Use Committee (IACUC). 6-8 weeks old male BALB/cJ mice were injected intramuscularly (IM) into the tibialis anterior of the right hind limb. Total injected volume was $20 \mu \mathrm{l}$. Splenocytes and plasma were collected. All procedures with rAds were performed under BSL-2, and all vector treated animals were maintained in ABSL-2 conditions. Care for mice was provided in accordance with PHS and AAALAC standards.

\section{ELISA}

ELISA-based antibody assays were completed as previously described [16]. High-binding flat bottom 96-well plates were coated with $0.2 \mu \mathrm{g}$ of purified CSP per well in a volume of $100 \mu \mathrm{L}$ and incubated overnight at $4^{\circ} \mathrm{C}$. Plates were washed with PBS-Tween $(0.05 \%)$ then treated with blocking buffer ( $3 \%$ bovine serum albumin) for 1 hour at room temperature. Plasma from ad naïve animals was diluted $(1: 100,1: 200,1: 400)$ in blocking buffer. Plasma from Ad immune animals was analysed without dilution. Samples were incubated for 1 hour at room temperature. Wells were washed with PBS-Tween (0.05\%) and HRP antibody (Bio-Rad) was added at 1:4,000 dilution in PBS-Tween. Tetramethylbenzidine (TMB) (Sigma-Aldich) was added to each well and the reaction was stopped with $2 \mathrm{~N}$ sulfuric acid. Plates are read at $450 \mathrm{~nm}$ in a microplate spectrophotometer. Subisotyping titering was completed with a hybridoma subisotyping kit (Calbiochem, La Jolla, CA) with plasma dilutions of 1:100, 1:200 and 1:400. Statistical analyses were performed using Student $t$-test.

\section{Isolation of lymphocytes}

Splenocytes from individual mice were prepared by physical disruption of the spleen. The spleen was passed through a sterile $40 \mu \mathrm{m}$ nylon mesh cell strainer (Fisher Scientific, Pittsburgh, PA). Red blood cells were lysed using ACK lysis buffer (Invitrogen, Carlsbad, CA) remaining cells were resuspended in RPMI 1640 supplemented with 10\% FBS and penicillin/streptomycin/ fungizone [35].

\section{ELISPOT analysis}

ELISpots were performed in accordance to manufacturer's protocol using the Ready-set Go IFNY mouse ELISpot kit produced by eBiosciences (San Diego, CA). Splenocytes were stimulated ex vivo with $4 \mu \mathrm{g} / \mathrm{mL}$ of the $>98 \%$ pure CSP immunodominant peptide NYDNAGTNL (amino acids 43-51 of the CSP sequence) (GenScript Piscataway, NJ) [36]. Spots were counted and photographed by an automated ELISPOT reader system (Cellular Technology, Cleveland, OH). Ready-set Go IFN $\gamma$ and IL-2 mouse ELISPOT kits purchased from eBioscience (San Diego, CA).

\section{Cell staining and flow cytometry}

Splenocytes were stained with various combinations of the following antibodies: APC-Cy7-CD3, Alexa Floure700CD8, PerCpCy5.5-CD127, PE-Cy7-CSP (NYD) tetramer, V450-CD62L, PE-Cy7-TNF $\alpha$, APC-IFN $\gamma$, and Granzyme B- $(4 \mu \mathrm{g} / \mathrm{ml})$ (All obtained from BD Biosciences, San Diego, CA). Cells were incubated on ice with the appropriate antibodies for 30 minutes, washed, and sorted using an LSR II instrument and analysed using FlowJo software. For intracellular cytokines staining, cells were surface stained, fixed with $2 \%$ formaldehyde (Polysciences, Warrington, PA), permeabilized with $0.2 \%$ saponin (Sigma-Aldrich, St. Louis, MO), and stained for intracellular cytokines. Large cells and debris were excluded in the forward- and side-scatter plot, to minimize background levels of staining caused by nonspecific binding of antibodies; cells were initially stained with CD16/32 FcR III/II antibody. In addition the violet fluorescent reactive dye (ViViD, Invitrogen) was used as a viability marker to exclude dead cells from the analysis [37]. Blood was isolated by retro-orbital bleeds and PBMCs were isolated using Lympholyte-Mammal (Cedarlane, Burlington NC). Tetramer staining of PBMCs was completed using a PE conjugated MHC-I (H2d) tetramer folded with the NYDNAGTNL peptide generated at the NIH Tetramer Core Facility.

\section{In vivo $C T L$ assay}

$\mathrm{BALB} / \mathrm{cJ}$ were injected with a priming dose of $1 \times 10^{10}$ $\mathrm{vp} /$ mouse of either Ad5-CSP or Ad4-CSP followed by a heterologous or homologous boosting injection of 
$1 \times 10^{10} \mathrm{vp} / \mathrm{mouse} 14$ days after the initial injection. At 28 days post initial injection, syngeneic splenocytes were isolated and pulsed with either an irrelevant peptide or peptide specific to the $P$. falciparum circumsporozoite antigen (NYDNAGTNL) for 1 hour at $37^{\circ} \mathrm{C}$. Irrelevant peptide pulsed cells were stained with $1 \mu \mathrm{M}$ CFSE $\left(\mathrm{CFSE}^{\mathrm{Low}}\right)$ while CSP-peptides pulsed cells were stained with $10 \mu \mathrm{M}$ CFSE (CFSE $\left.{ }^{\text {High }}\right)$. Naïve and immunized mice were injected with equivalent amount of both $\mathrm{CFSE}^{\text {Low }}$ and $\mathrm{CFSE}^{\text {High }}$ stained cells via the retro-orbital sinus. After 18 hours splenocytes were harvested and sorted on an LSRII flow cytometer. FlowJo software was used to determine percentages of CFSE stained cells. \% Specific killing = 1-((\% CFSE ${ }^{\text {High }} / \%$ CFSE $\left.^{\text {Low }}\right)_{\text {immunized }} /$ (\% $\left.\mathrm{CFSE}^{\mathrm{High}} / \% \mathrm{CFSE}^{\mathrm{Low}}\right)_{\text {non-immunized }}$ ).

\section{Statistical analysis}

Statistically significant differences in ELISpot assays were determined using either Two Way ANOVA with a Bonferroni post-hoc test or a One Way ANOVA with a Student-Newman-Keuls post-hoc test ( $\mathrm{p}$ value $<0.05$ ). For ELISA analysis, a t-test was used to assess significance between treatments. For multiparameter flow cytometry, a One Way ANOVA with a Student-Newman-Keuls post-hoc test was used. For in vivo CTL assay, a One Way ANOVA with a Student-Newman-Keuls post-hoc test was used. All graphs in this paper are presented as Mean \pm SD with the exception of ELISA graphs, which use Mean \pm SE. GraphPad Prism software was utilized for statistical analysis.

\section{Results}

rAds of serotype 4 and serotype 5 were engineered to express a codon optimized form of CSP using methods previously described $[33,34]$. Four vaccination regimens were utilized; 1. Ad5-CSP/Ad5-CSP, 2. Ad5-CSP/Ad4CSP, 3. Ad4-CSP/Ad4-CSP, and 4. Ad4-CSP/Ad5-CSP, where the Ad serotype used in the priming vaccination is immediately followed by the serotype of the boosting vaccination in each vaccine regimen or group. Initially, (day 0) Ad naïve BALB/cJ mice were injected with either Ad4-CSP or Ad5-CSP $\left(1 \times 10^{10} \mathrm{vp} /\right.$ mouse) $(\mathrm{n}=10) .14$ days later 5 mice from each treatment group received a homologous boost (same Ad-CSP serotype vaccine) of $1 \times 10^{10}$ $\mathrm{vp} / \mathrm{mouse}$, the other five mice from the same group received a heterologous boosting vaccination of $1 \times 10^{10}$ $\mathrm{vp} /$ mouse with the alternative Ad-CSP serotype vaccine. 28 days after the priming vaccinations, splenocytes were harvested from the animals and stimulated with the CSP derived peptide (NYDNAGTNL) and the number of IFNY secreting splenocytes were quantified by ELISpot. While every vaccine treatment resulted in a significant increase in the numbers of CSP responsive INF $\gamma$ secreting splenocytes when compared to non-vaccinated animals, the Ad4-CSP/Ad5-CSP heterologous prime boosting vaccine treatment group induced significantly higher numbers of IFNy secreting splenocytes than any other treatment group (Figure 1A). Of note, previous experiments have confirmed that simple administration of Ad vaccines does not significantly increase numbers of IFNy secreted cells, for example when splenocytes derived from Ad vaccine treated animals are stimulated with control peptides [33-35]. These results were further supported by intracellular staining with antibodies against CD3, CD8, and IFN $\gamma$, as the percentage of CSP responsive $\mathrm{CD}^{+} \mathrm{CD}^{+} \mathrm{IFN}^{+}$cells present in splenocytes derived from mice vaccinated with the Ad4-CSP/ Ad5-CSP regimen were significantly higher when compared to splenocytes from animals treated with the other vaccination strategies (Figure $1 \mathrm{~B}$ ). Intracellular staining was also performed to enumerate the frequency of TNF and Granzyme B producing $\mathrm{CD}^{+} \mathrm{T}$ cells present in the spleens of the variously vaccinated animals. Again, the Ad4-CSP/Ad5-CSP experimental vaccination regimen appeared to confer the most robust immune responses against CSP, as it was the only treatment to induce significantly higher percentages of CSP responsive $\mathrm{CD}^{+}$ $\mathrm{CD}^{+} \mathrm{TNF}^{+}$cells as compared to non-vaccinated animals (Figure 1C). Interestingly, none of the vaccination strategies induced significantly higher percentages of CSP responsive $\mathrm{CD}^{+} \mathrm{CD}^{+}$Granzyme $\mathrm{B}^{+}$cells as compared to non-vaccinated animals; however, animals from the Ad5-CSP/Ad4-CSP vaccination group had significantly lower percentages of $\mathrm{CD}^{+}, \mathrm{CD}^{+}$, Granzyme $\mathrm{B}^{+} \mathrm{T}$ cells as compared to all other treatment groups (Figure 1D).

As detected by use of the NYDNAGTNL tetramer, each of the vaccination regimens induced significantly higher percentages of $\mathrm{CD}^{+} \mathrm{CD}^{+} \mathrm{T}$ cells in the spleen as compared with non-vaccinated control animals $(p<0.001)$ (Figure 2A). Of the four groups, the Ad4-CSP/Ad5-CSP heterologous prime boosting regimen induced the lowest percentage of $\mathrm{CD}^{+} \mathrm{CD}^{+}$tet $^{+} \mathrm{T}$ cells, a decrease that was statistically significant as compared to both the Ad5-CSP/ Ad5CSP and the Ad5-CSP/Ad4-CSP treatment groups $(p<0.01 ; p<0.05$ respectively). When peripheral blood mononuclear cells (PBMCs) from the vaccinated mice were similarly analysed, again all groups of vaccinated mice had significantly increased numbers of $\mathrm{CD}^{+} \mathrm{CD}^{+}$ tet $^{+} \mathrm{T}$ cells present as compared to non-vaccinated mice. However, the Ad4-CSP/Ad4-CSP treated animals elicited the lowest percentages of $\mathrm{CD}^{+} \mathrm{CD}^{+}$tet $^{+} \mathrm{T}$ cells of the four groups, this decrease reaching statistical significance when this group was compared to both the Ad5-CSP/ Ad5-CSP and Ad5-CSP/Ad4-CSP treatment groups $(p<0.05$ for each group) (Figure $2 \mathrm{~B})$.

Ad vectors are known to elicit strong $\mathrm{T}_{\mathrm{em}}$ cell responses thought to be due to more persistent antigen 


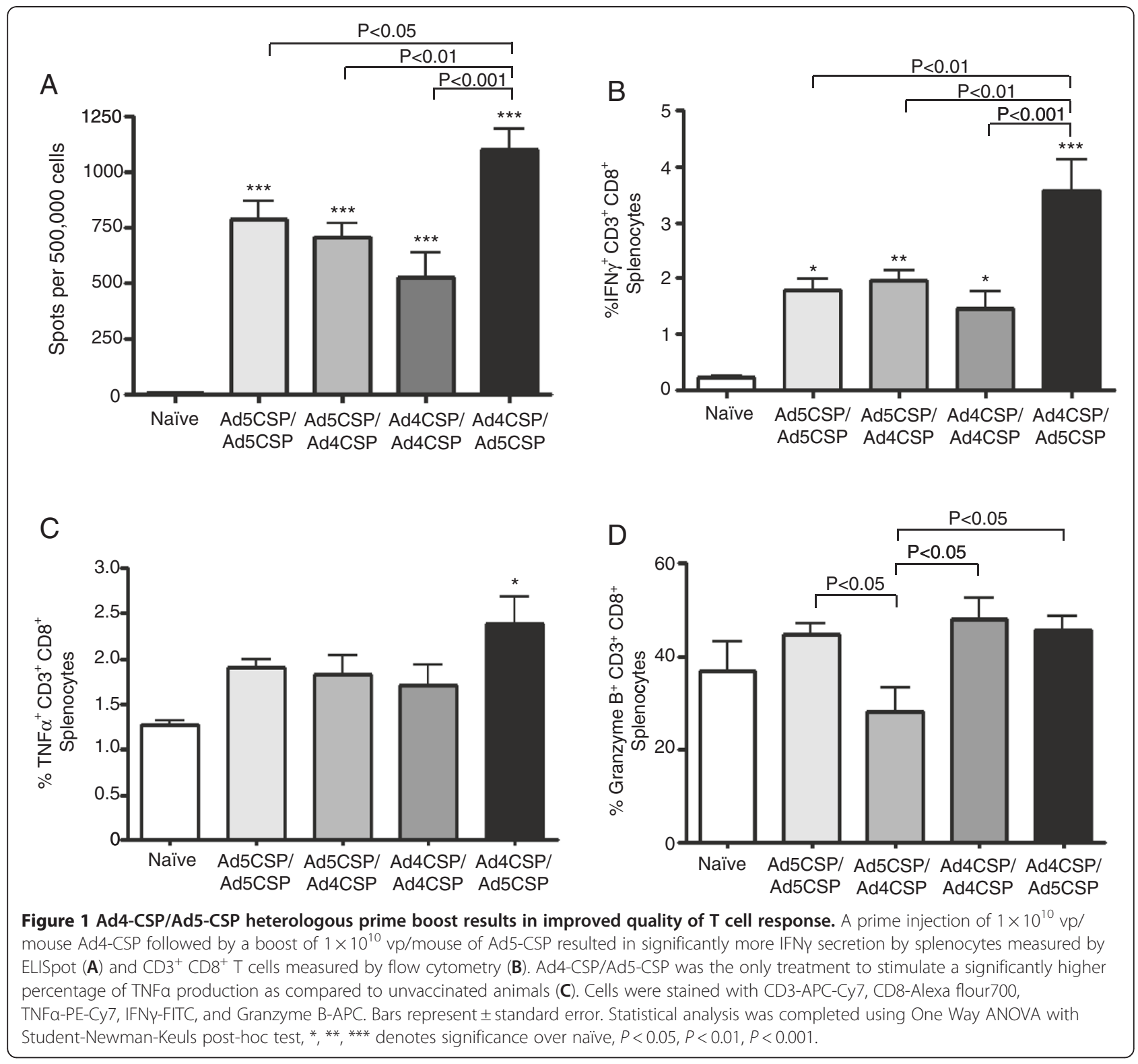

production. This is important in the context of a malaria vaccine as $T_{e m}$ cell responses have been shown to be beneficial in protecting against liver stage malaria [38]. The magnitude of CSP-specific central memory and effector memory $\mathrm{CD}^{+} \mathrm{T}$ cell responses was compared in each of the various prime boost regimens induced in splenocytes and PBMCs harvested 14 days after the boosting vaccinations. All prime boost regimens demonstrated much higher percentages of CSP specific $\mathrm{T}_{\mathrm{cm}}$ cells and $\mathrm{T}_{\mathrm{em}}$ cells than was observed in non-vaccinated animals as indicated by the percent of $\mathrm{CD} 127^{+} \mathrm{CD}^{\mathrm{C}} 2 \mathrm{~L}^{+}$ and $\mathrm{CD} 127^{+} \mathrm{CD}^{-} \mathrm{L}^{-}$tet $^{+} \mathrm{T}$ cells present in the splenocytes (Figure 3B-C). The percentage of CSP specific $\mathrm{T}_{\mathrm{cm}}$ and $\mathrm{T}_{\mathrm{em}}$ cells circulating in the blood was also analysed and it was found that the Ad5-CSP/Ad4-CSP vaccination group was the only group that had a significantly higher percentage of CSP specific $\mathrm{T}_{\mathrm{cm}}$ cells in circulating blood when compared to non-vaccinated animals, while all vaccinated animals had higher percentages of CSP specific $\mathrm{T}_{\mathrm{em}}$ cells present in this compartment as compared to non-vaccinated animals (Figure 3D-E). When memory phenotypes were analysed by gating on tetramer positive cells first, followed by gating for CD127 and CD62L, the tetramer positive cells of all groups had similar memory phenotypes as defined by comparison of the percentages of tet ${ }^{+}$cells that were $T_{e m}$ and those that were $T_{c m}$ cell.

Splenocytes from all treatments were analyzed for the presence of anti-Ad4 and/or anti-Ad5 antigen specific IFN $\gamma$ secreting $\mathrm{T}$ cells by ELISpot. There was no significant cross stimulation between the two serotypes 

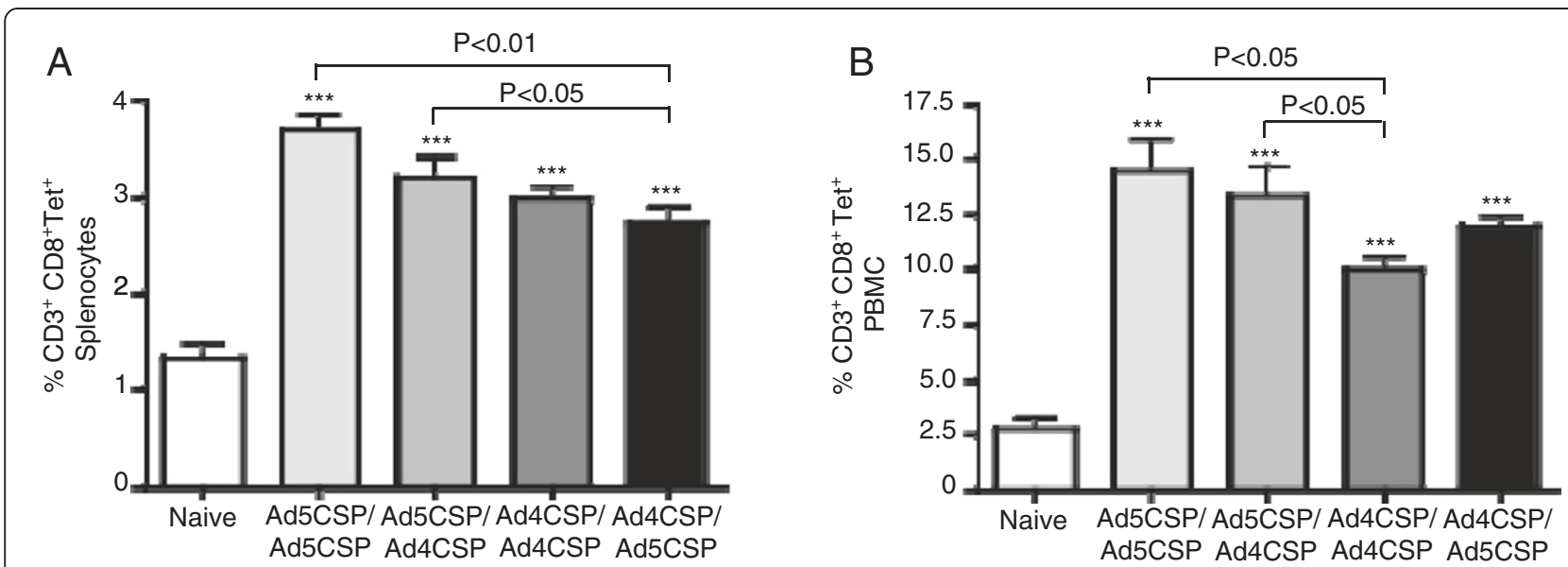

Figure 2 Ad5-CSP/Ad5-CSP vaccination resulted in higher percentage of tetramer positive CD8 ${ }^{+} \mathrm{T}_{\text {cells }}$ than Ad4-CSP/Ad5-CSP in the spleen. Splenocytes and PBMCs were collected two weeks after final vaccination. All vaccination regimens resulted in significantly higher percentage of $\mathrm{CD}^{+} \mathrm{CD}^{+}$NYDNAGTNL tetramer positive T cells in the spleen $(\mathbf{A})$ and circulating blood (B) as measured by flow cytometry, cells were stained with CD8-Alexa flour700, CD3-APC-Cy7, and CSP (NYD)-Tetramer-PE. Ad5-CSP/Ad5-CSP stimulated a higher percentage of CD3 ${ }^{+}$CD8

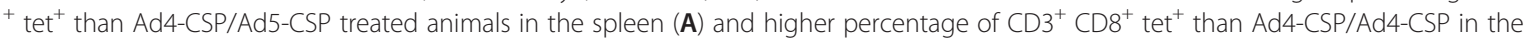
circulating blood (B). Bars represent \pm standard error. Statistical analysis was completed using One Way ANOVA with Student-Newman-Keuls posthoc test, ${ }^{*} *^{* *}, * * *$ denotes significance over naïve, $P<0.05, P<0.01, P<0.001$.

detected by this assay, as animals that received Ad4CSP/Ad4-CSP treatment had significantly less Ad5 specific IFN $\gamma$ secreting cells than all other vaccination regimens, and were not significantly different than naive animals. Likewise, animals that were vaccinated with Ad5-CSP/Ad5-CSP had significantly less Ad4 specific IFN $\gamma$ secreting cells than animals that received Ad4-CSP injections and were also not significantly different than naïve animals (Additional file 1 ).

The effect of prime boost vaccinations combining Ad4-CSP and Ad5-CSP on CSP specific antibody production, as compared to homologous prime boosts using the same vectors was then determined. Plasma was collected from BALB/cJ mice injected with the four prime boost regimens 28 days post initial injection and was tested by ELISA for total anti-CSP IgG antibody levels. Mice from the Ad4-CSP/Ad4-CSP vaccination group demonstrated significantly higher plasma levels of IgG anti-CSP relative to unvaccinated animals at the 1:100 dilutions $(p<0.05)$ (Figure 4$)$. All other vaccination regimens induced significantly higher levels of anti-CSP IgG as compared to both the non-vaccinated animals and animals receiving the Ad4-CSP/Ad4-CSP regimen $(p<0.001)$ (Figure 4). Similar trends were observed when sub-isotyping analysis was performed for anti-CSP IgG1, IgG2a, IgG2b, and IgG3 levels (Additional file 2). IgG2a/IgG1 ratio was analysed as an indirect assessment of $\mathrm{T}_{\mathrm{h}} 1$ vs. $\mathrm{T}_{\mathrm{h}} 2$ immune responses in animals treated with the vaccine regimens; however the $T_{h} 1 / T_{h} 2$ ratio was not significantly different with use of any of the vaccination regimens (Additional file 3).
To assess the efficacy of Ad4 based vaccination regimens to induce functional, CSP specific cytolytic $\mathrm{T}$ cell responses, CSP specific cytotoxic $\mathrm{T}$ lymphocyte killing in vivo was measured. BALB/cJ mice were vaccinated with the homologous and heterologous prime boost regimes as described above. 28 days after the initial vaccination, splenocytes from naïve mice were collected and incubated with either a high concentration of CFSE $(10 \mu \mathrm{M})$ and NYDNAGTNL peptide or a low concentration of CFSE $(1 \mu \mathrm{M})$ and a non-specific peptide. Stained and peptide pulsed splenocytes were then mixed at equal quantities and injected intravenously into vaccinated or non-vaccinated animals. After 18 hours, CSP specific cell killing was measured in the spleens of the vaccinated animals by flow cytometry. Only animals that received the Ad5-CSP/Ad5-CSP and Ad4-CSP/Ad5-CSP vaccination regimens achieved significantly elevated levels of CSP specific cell killing as compared to non-vaccinated animals $(p<0.01)$ (Figure 5).

Given the high seroprevalence of wild type Ad5 in adults living in malaria endemic regions, the ability of these homologous and heterologous prime boost vaccine regimens to elicit potent CSP specific adaptive responses was also analysed in animals that were made Ad5 immune prior to receipt of the various vaccine regimens. $\mathrm{BALB} / \mathrm{cJ}$ mice received two injections 14 days apart of $1 \times 10^{10} \mathrm{vp} /$ mouse of an Ad5 vector that does not express a transgene (Ad5-Null). It has been previously demonstrated that two immunizations with $1 \times 10^{10}$ vps of rAd5-Null vector induced Ad5 neutralizing antibodies titers that were $>1 / 200$, a level that closely parallels 


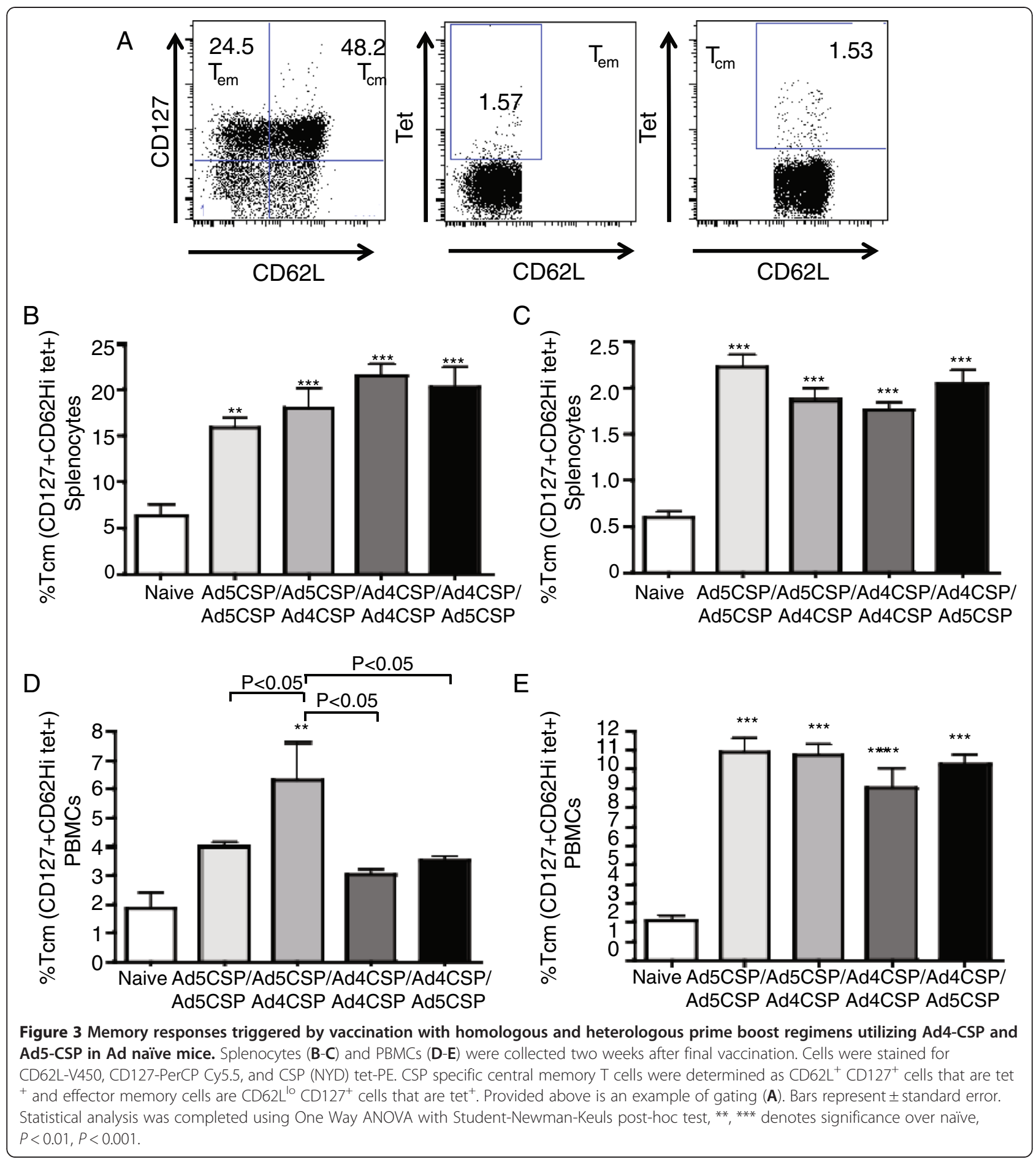

levels of pre-existing Ad5 immunity noted in human populations [39]. 14 days after the last injection of Ad5Null, Ad5-immune animals received $1 \times 10^{10} \mathrm{vp} /$ mouse prime injection of either Ad4-CSP or Ad5-CSP followed by either a heterologous or homologous boost 14 days after the initial priming vaccination. 28 days after the prime vaccination plasma, PBMCs, and splenocytes were collected. Splenocytes were stimulated as before with NYDNAGTNL and were analyzed for CSP specific IFN $\gamma$ secreting cells by ELISpot. Ad5-CSP/Ad4-CSP, Ad4CSP/Ad4-CSP, and Ad4-CSP/A5-CSP vaccinated Ad5 immune animals all had significantly higher numbers of NYDNAGTNL responsive IFN $\gamma$ secreting cells present when compared to the Ad5-CSP/Ad5-CSP cohort or 


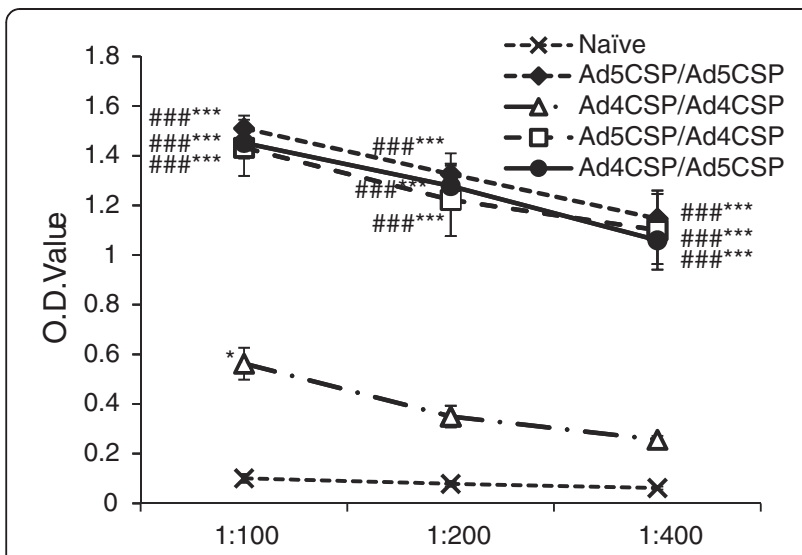

Figure 4 All vaccinations stimulated significantly higher anti-CSP total lgG than unvaccinated and AD4-CSP/Ad4-CSP vaccination in Ad naïve animals. Plasma was collected 14 days post the final vaccination. Plasma was diluted 1:100, 1:200, and 1:400 and measured for total IgG against CSP by ELISA. Bars represent \pm standard error. Statistical analysis was completed using One Way ANOVA with Student-Newman-Keuls post-hoc test, ${ }^{*},{ }^{* *}$, *** denotes significance over naïve, $P<0.05, P<0.01, P<0.001$. \#\#\# denotes significance over Ad4-CSP/Ad4CSP treatment, $P<0.001$.

the non-vaccinated animals (Figure 6). However, as compared to Ad5 naive animals, overall induction of NYDNAGTNL responsive, IFNY secreting splenocytes was

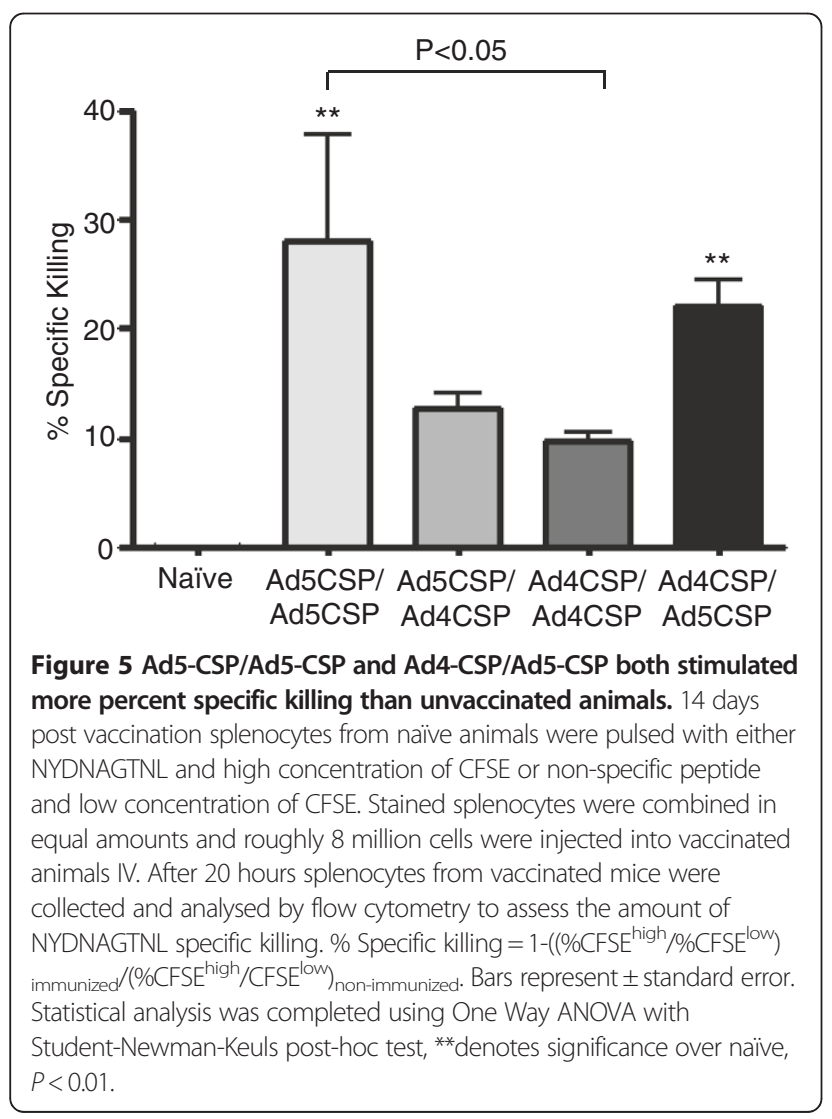

notably diminished in Ad5 immune animals despite use of Ad4-CSP in some of the regimens (Table 1). The reductions prevented detection of significant differences between the treatments when ICS of the splenocytes for IFN , TNF, and Granzyme B was undertaken (Additional file $4 \mathrm{~A}-\mathrm{C})$.

PBMCs and splenocytes were then analysed for $\mathrm{CD}^{+}$ $\mathrm{CD}^{+} \mathrm{T}$ cells that were CSP peptide tetramer binding by flow cytometry and found that all vaccinated Ad5 immune animals, including Ad5-CSP/Ad5-CSP vaccinated animals, had a significantly higher percentage of CSP specific $\mathrm{CD}^{+} \mathrm{CD}^{+}$tet $^{+} \mathrm{T}$ cells present in both the spleen and peripheral blood (Figure 7A-B). All treatments including Ad5-CSP/Ad5-CSP also had significantly higher percentages of tetramer positive $T_{c m}$ cells when compared to the non-vaccinated animals in both the spleen and in the peripheral blood (Figure 8B, D). Only mice from the Ad5-CSP/Ad5-CSP treatment group had higher frequencies of CSP specific $\mathrm{T}_{\mathrm{em}}$ cells in their spleens as compared to non vaccinated mice (Figure $8 \mathrm{C}$ ). Ad5-CSP/Ad5-CSP, Ad5-CSP/Ad4-CSP, and Ad4-CSP/ Ad4-CSP vaccination groups all stimulated significantly more $\mathrm{T}_{\mathrm{em}}$ cells in the peripheral blood than non-vaccinated and Ad4-CSP/Ad5-CSP vaccinated Ad5 immune-animals (Figure 8E). T cells memory phenotypes were measured and it was found that homologous prime boost vaccinations biased the $\mathrm{T}$ cell

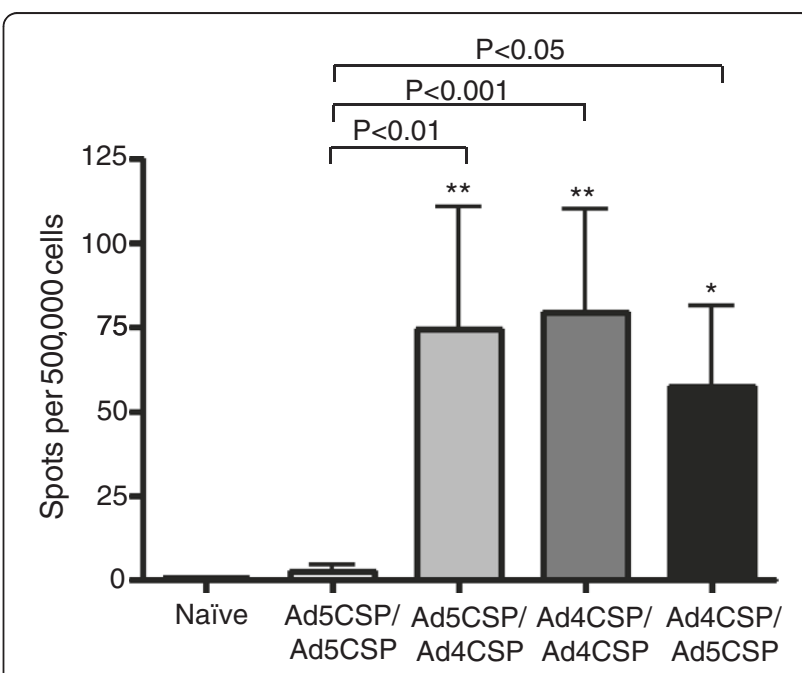

Figure 6 IFNy secretion of cells from Ad5 immune mice vaccinated with heterologous and homologous prime boost regimens utilizing Ad4-CSP and Ad5-CSP. All vaccinations were capable of stimulating significantly more IFNy secreting cells than unvaccinated and Ad5-CSP/Ad5-CSP vaccinated Ad5 immune animals. Splenocytes were collected 14 days after final vaccination. Splenocytes were then stimulated with CSP dominant antigen NYDNAGTNL and IFNY secretion was measure by ELISpot. Bars represent \pm standard error. Statistical analysis was completed using One Way ANOVA with Student-Newman-Keuls post-hoc test, $*$, ** denotes significance over naïve, $P<0.05, P<0.01$. 
Table 1 Decreased mean spot forming cells in Ad5 immune animals

\begin{tabular}{lll}
\hline Vaccination & Ad5 naive & Ad5 immune \\
\hline Naive & 2.71 & 2.71 \\
Ad5-CSP/Ad5-CSP & 791.25 & 2.80 \\
Ad5-CSP/Ad4-CSP & 708.00 & 74.50 \\
Ad4-CSP/Ad4-CSP & 527.20 & 79.60 \\
Ad4-CSP/Ad5-CSP & 1100 & 57.60 \\
\hline
\end{tabular}

All vaccinations, inclusive of homologous Ad4-CSP prime boost, elicited fewer IFNY secreting splenocytes in Ad5 immune animals as measured by ELISpot. The table displays the mean numbers of spot forming cells per 500,000 splenocytes from spleens of $\mathrm{Ad} 5$ naïve and $\mathrm{Ad} 5$ immune mice treated with each prime boost regimen.

responses toward $\mathrm{T}_{\mathrm{cm}}$ rather than $\mathrm{T}_{\mathrm{em}}$ cell phenotype memory in Ad5 immune mice (Figure 9). The in vivo cytolytic activity of $\mathrm{CD}^{+} \mathrm{T}$ cells in Ad5 pre-immune mice was also evaluated. No significant increase in percent specific killing was observed in any treatment groups when compared to unvaccinated Ad5 immune animals (data not shown). Undiluted plasma collected from unvaccinated animals and Ad5 immune animals from each vaccination regimen was analysed for antiCSP total IgG by ELISA. From the undiluted plasma, it was found that Ad5-CSP/Ad4-CSP, Ad4-CSP/Ad4-CSP, and Ad4-CSP/A5-CSP vaccinated animals all had significantly more CSP specific total IgG than non-vaccinated animals $(p<0.001)$ and the Ad5 immune animals homologously vaccinated with Ad5-CSP $(p<0.001)$ (Figure 10).

\section{Conclusions}

Ad4 has many qualities that make it a desirable choice as a vaccine platform, inclusive of an ability to induce robust early innate responses and a high rate of infectivity [34]. Ad4 also has a long history of use as a vaccine being used as an enteric live Ad4 vaccine by the military to vaccinate recruits against ARD [29-32]. For these reasons Ad4 has already been utilized as a potential HIV vaccine vector in several large animal HIV models [24,25]. This study investigated how Ad4 based vaccines might be incorporated into malaria vaccine regimens, either in isolation, or in combination with a first generation Ad5 vaccine platform.

The combination of a priming vaccination of Ad4-CSP boosted by Ad5-CSP in Ad5 naïve animals results in induction of higher levels of activated $\mathrm{CD}^{+} \mathrm{T}$ cells than any other vaccination regimen used in this study. The activated $\mathrm{T}$ cells induced by an Ad4-CSP priming vaccination boosted by Ad5-CSP are also capable of potent CSP specific killing to levels that are equivalent to use of Ad5-CSP homologous vaccinations, despite the fact that animals homologously vaccinated with Ad5-CSP had higher levels of CSP specific $\mathrm{CD}^{+} \mathrm{T}$ cells detectable by staining with antibodies for CD3, CD8, and tetramer specific for CSP. These data suggest that combined use of Ad4-CSP priming followed by an Ad5-CSP boosting vaccination induced more efficient cytotoxic $\mathrm{T}$ cell killers than those induced by homologous prime boost of Ad5CSP. If the aim is to provide a large quantity of CSP reactive $\mathrm{T}$ cells, a homologous prime boost vaccination of Ad5-CSP should be utilized. However, if one wishes to elicit IFNY and TNF secreting T cells specific for CSP, these results suggest that a priming vaccination with Ad4-CSP followed by a boosting vaccination with Ad5CSP may be preferable.

While Ad4-CSP provided benefit when utilized as a priming vaccination prior to boosting with Ad5-CSP,

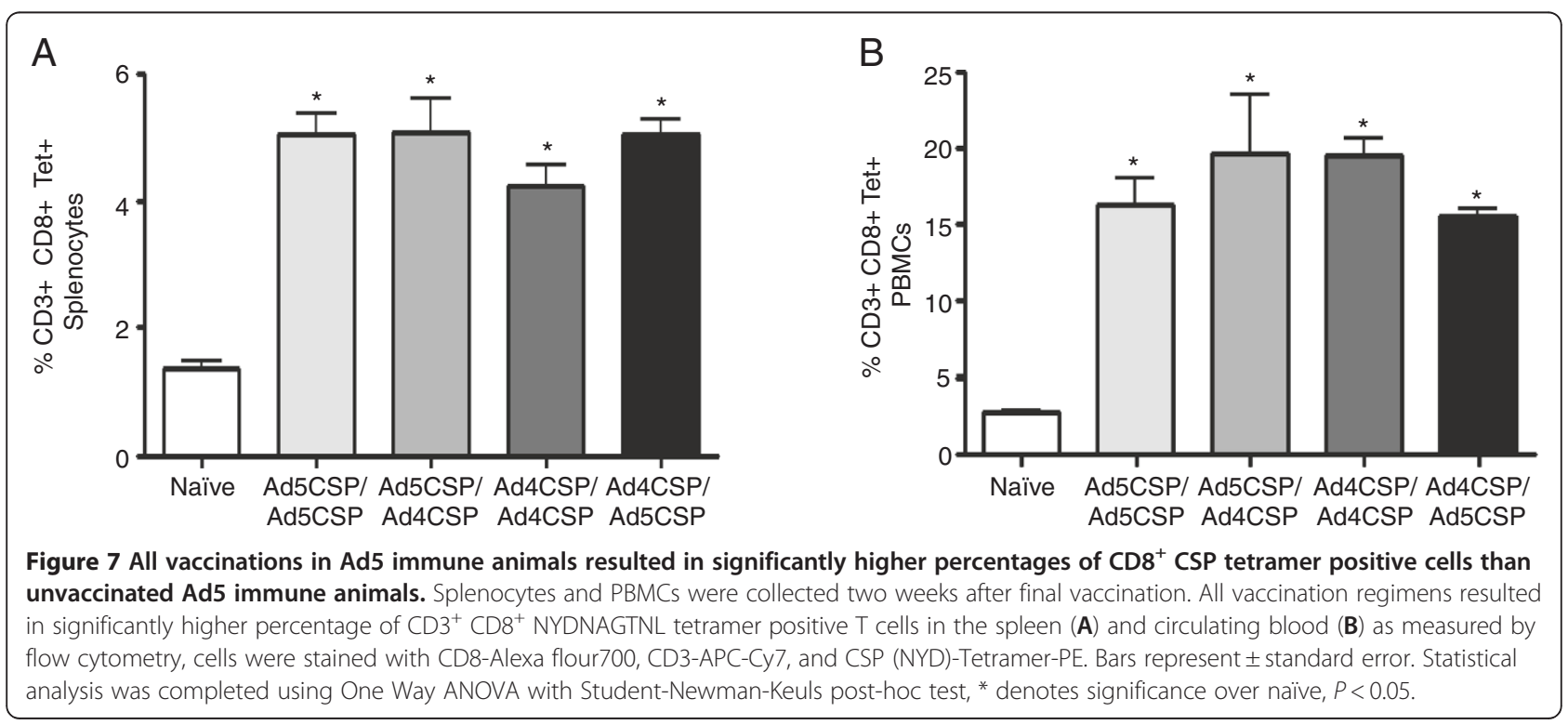




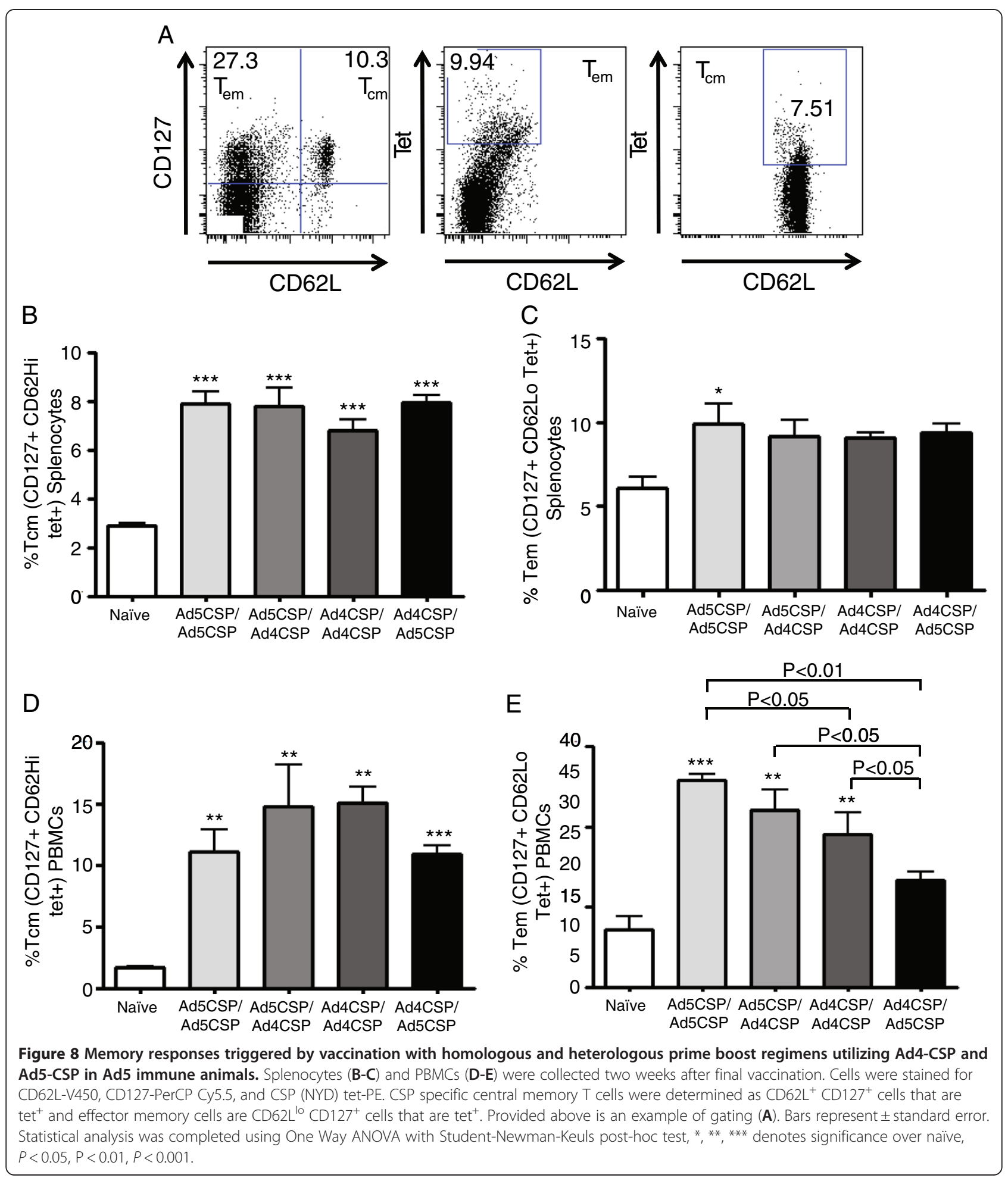

Ad4 was not as capable as Ad5-CSP when attempting to stimulate potent CSP specific immune responses in homologous prime boost regimens. Additionally, boosting a prime of Ad5-CSP with Ad4-CSP induced very poor CSP specific immune responses in general.
Diminished induction by Ad4 based vaccines of transgene-specific IgG has been previously observed, and the effect was suggested to be a result of the Ad4 capsid inducing high levels of IFN- $\beta$, interfering with the CMV promoter used to drive expression of the antigen 


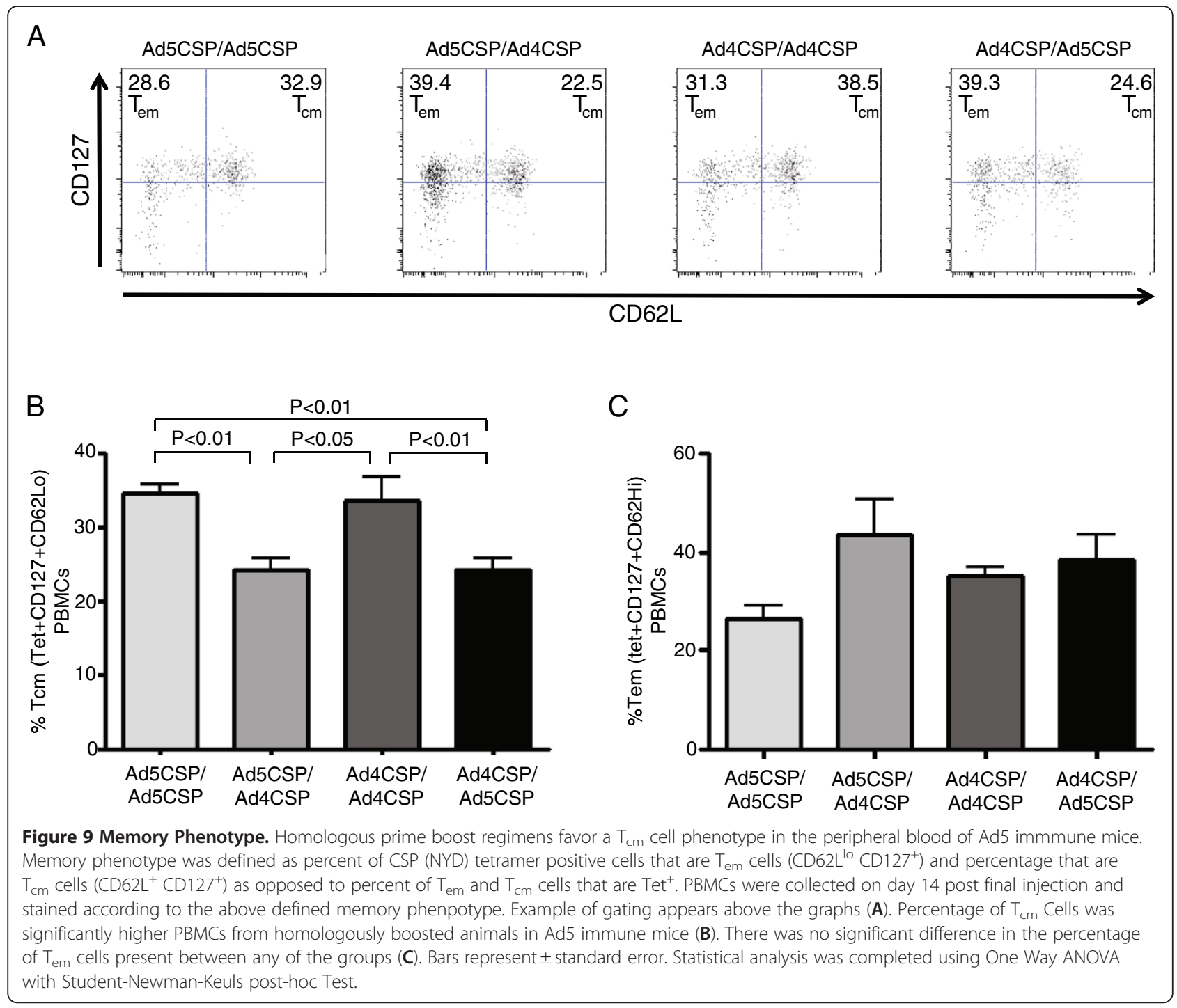

encoding transgene. Interference with the CMV promoter may ultimately reduce the length of time the CSP antigen is expressed from Ad4 vaccine platforms, and may explain the decrease in efficacy when Ad4-CSP is utilized in isolation or as a boosting vaccination in current studies [34].

To obtain protection from liver stage malaria, the presence of $\mathrm{T}_{\mathrm{em}}$ cells are thought to be an essential element and a significant correlate to predicting vaccine efficacy [38]. Among the vaccination regimens, the induction of CSP specific $\mathrm{T}_{\mathrm{em}}$ cell and $\mathrm{T}_{\mathrm{cm}}$ cells were grossly similar when Ad4 or Ad5 based CSP vaccine treatments were conducted in Ad naïve animals. However, vaccination regimens did not perform equally when in vivo cytotoxicity was tested, as only the animals receiving an Ad4-CSP priming vaccination boosted by Ad5-CSP, and the animals receiving the homologous Ad5-CSP prime-boost vaccination regimens resulted in detection of significantly improved levels of CSP specific cell killing, as compared to non-vaccinated animals. Since 14 days post vaccination is within the time frame when peak $\mathrm{CD}^{+}$effector $\mathrm{T}$ cell responses may be present, and $\mathrm{CD} 8^{+} \mathrm{T}$ cell contraction usually does not take place until after three weeks post-vaccination, it is likely that the observed CSP specific killing is a result of the lingering presence of $\mathrm{CD}^{+}$effector $\mathrm{T}$ cells, rather than induction of $\mathrm{T}_{\mathrm{em}}$ cells.

Another reason to undertake these studies was to determine if the use of serologically distinct Ad4 based malaria targeted vaccines might allow for improved induction of CSP immune responses, relative to repeated use of Ad5, in Ad5 immune animals. Indeed, Ad4-CSP was capable of stimulating the induction of significantly more CSP antigen specific IFN $\gamma$ secreting splenocytes, as well as higher levels of anti-CSP antibodies when incorporated into prime boost regimens in Ad5 immune 


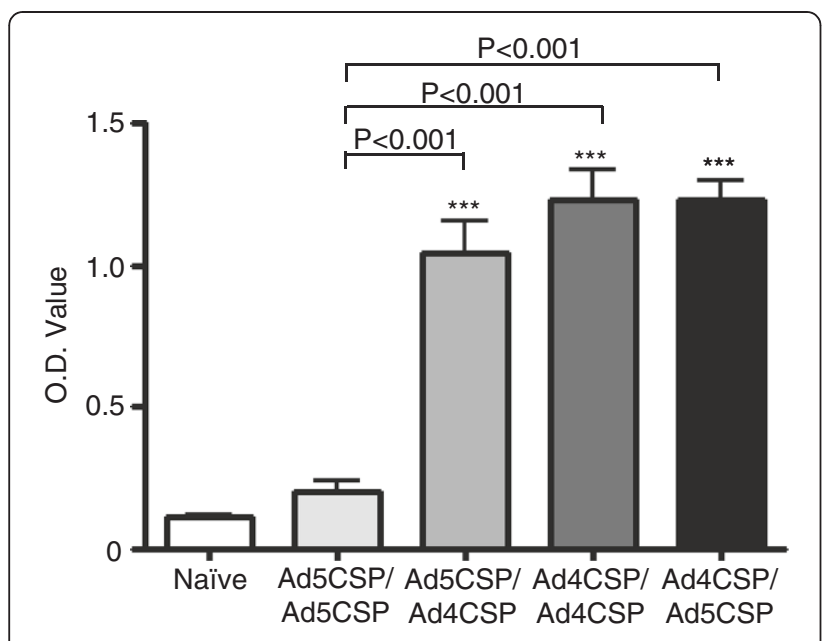

Figure 10 All vaccinations stimulated significantly higher anti-CSP total IgG than unvaccinated and Ad5-CSP/Ad5-CSP vaccination in Ad5 immune animals. Plasma was collected 14 days post the final vaccination. Plasma was measured undiluted for total lgG against CSP by ELISA. Serial dilutions were not possible as the undiluted plasma data point required the majority of the plasma collected from an animal. Bars represent \pm standard error. Statistical analysis was completed using One Way ANOVA with Student-Newman-Keuls post-hoc test, ${ }^{* *}$ denotes significance over naïve, $P<0.001$.

mice (as compared to use of the Ad5-CSP vaccine). However, these levels were below what was observed when the Ad4-CSP vaccine was utilized in Ad5 naïve animals. Furthermore, functional analysis suggested that use of Ad4 in Ad5 immune animals also did not result in improved induction of CSP specific cytotoxic activity as compared to non-vaccinated animals. Although Ads are segregated into subgroups based primarily on antisera neutralization there is evidence that $\mathrm{T}$ cell responses can react across Ad subgroups in humans [40]. These cross reactive $\mathrm{T}$ cells could be responsible for the decreased immunogenicity observed in Ad5 immune animals homologously vaccinated with Ad4-CSP. Therefore, a priori assumptions regarding lack of likely cross neutralization by utilizing different subgroups of adenovirus must be reconsidered in light of these types of functional, in vivo data. Likely, mild cross reactivity not measured by conventional means (such as the neutralizing antibody and ELISpot based assays used in this study) is still capable of diminishing immunogenicity of two very distinct serotypes on the basis of perhaps only a few cross reactive epitopes [41].

Prior immunity to Ad5 did not appear to affect the ability of any of the Ad4-CSP or Ad5-CSP vaccination regimens to induce CSP specific $\mathrm{CD}^{+}{ }^{+} \mathrm{T}$ cells. The percentages of CSP specific tetramer positive $\mathrm{CD}^{+} \mathrm{T}$ cells observed in Ad5 immune animals were similar to percentages observed in Ad naive animals. All vaccinations appeared to increase the percentage of $\mathrm{CD}^{+} \mathrm{T}$ cells specific to the CSP epitope NYDNAGTNL in Ad5 immune animals in spite of the observed ablation in cytokine production by these same cells. Similarly, all vaccinations except an Ad4-CSP prime boosted by Ad5CSP resulted in high percentages of CSP specific $T_{e m}$ cells in the circulating blood. Heterologous prime boost vaccinations even appear to trend toward a $\mathrm{T}_{\mathrm{em}}$ cell phenotype while homologous vaccinations biased toward a $T_{c m}$ cell phenotype. However, none of these responses correlated with evidence of improved in vivo CSP specific cytotoxic $\mathrm{T}$ cell killing when either of these vectors were deployed into Ad5 immune animals. Ad5 cross reactivity with Ad4 appears to result in the ablation of IFN $\gamma$ and TNF secreting CSP specific cytotoxic T cells induction by Ad4-CSP based vaccines, despite allowing for the induction of high percentages of CSP specific $T$ cells.

The data shows that there exists a complex interaction between immune responses triggered by a rAd4 (subgroup E) and those triggered by rAd5 (subgroup C), each expressing the same malaria antigen, in this instance, CSP. While combined use of Ad4-CSP priming vaccinations with Ad5-CSP boosting vaccinations results in the induction of greater numbers of CSP responsive cytokine secreting, cytotoxic T cells in Ad5 naïve animals, there appears to be interference between the two seemingly distinct Ad subgroups, resulting in diminished inductions of transgene specific immune responses in Ad5 immune animals despite the use of the Ad4 platform. Future studies need to be performed to further elucidate the mechanism behind Ad4's decreased ability to stimulate immune responses in an Ad5 immune background. Based on these results it is important that future use of alternative Ad serotypes be scrutinized under similarly stringent assay conditions to ascertain their true effectiveness in overcoming pre-existing Ad5 immunity.

\section{Additional files}

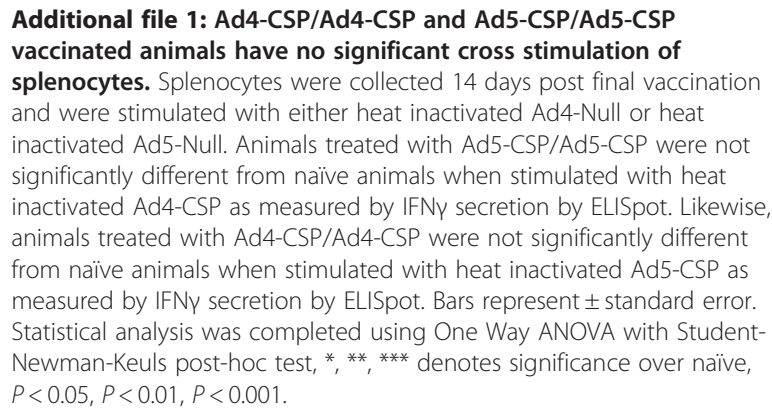

Additional file 2: Sub-isotype analysis of IgG antibody from plasma of mice vaccinated with heterologous and homologous prime boost regimens utilizing Ad4-CSP and Ad5-CSP. Plasma was collected 14 days post final vaccination. The amount of CSP specific subisotype $\lg G 1(A), \lg G 2 a(B), \lg G 2 b(C)$, and $\lg G 3(D)$ were analysed by ELISA. Bars 
represent \pm standard error. Statistical analysis was completed using One Way ANOVA with Student-Newman-Keuls post-hoc test, ${ }^{*}, * *, * * *$ denotes significance over naïve, $P<0.05, P<0.01, P<0.001$

\section{Additional file 3: Th1 to Th2 ratio (IgG2a/lgG1) of plasma from} vaccinated Ad naïve animals. Plasma was collected 14 days post final vaccination. The amount of CSP specific lgG subisotypes was measured by ELISA. Th1 to Th2 ratio was determined by dividing O.D. values from $\lg$ G2a and $\lg G 1$. Bars represent \pm standard error. Statistical analysis was completed using One Way ANOVA with Student-Newman-Keuls post-hoc test, ${ }^{*}$ denotes significance over naive, $P<0.05$.

Additional file 4: $\mathrm{CD}^{+} \mathrm{T}$ cell activation in $\mathrm{Ad} 5$ immune animals vaccinated with heterologous or homologous prime boost regimens utilizing Ad4-CSP and Ad5-CSP. Splenocytes were collected from vaccinated animals 14 days post the final vaccination. Cells were stained with CD8-Alexa flour700, CD3-APC-Cy7, TNFa-PE-Cy7, IFNY-FITC, and Granzyme B-APC and analysed by flow cytometry for INFY secreting $\mathrm{CD}^{+} \mathrm{CD}^{+} \mathrm{T}$ cells (A), TNFa secreting $\mathrm{CD}^{+} \mathrm{CD}^{+} \mathrm{T}$ cells (B), and granzyme $\mathrm{B}^{+} \mathrm{CD}^{+} \mathrm{CD}^{+} \mathrm{T}$ cells (C). Bars represent \pm standard error. Statistical analysis was completed using One Way ANOVA with Student-Newman-Keuls post-hoc test, ${ }^{*},{ }^{* *},{ }^{* * *}$ denotes significance over naïve, $P<0.05, P<0.01, P<0.001$

\section{Competing interests}

The authors declare that they have no competing interests.

\section{Authors' contributions}

NS Carried out animal injections, performed all ELISA, ELISpot and in vivo CTL assays, assisted with Ad5-CSP design and development, and drafted the manuscript. YA performed all other flow cytometry experiments. SG designed and developed Ad4-CSP and assisted with animal work. SS assisted with design and development of Ad4-CSP. YK designed and developed Ad5CSP. AA conceived of the study and participated in design and coordination. All authors read and approved the final manuscript.

\section{Acknowledgments}

We wish to thank Michigan State University Laboratory Animal support facilities for their assistance in the humane care and maintenance of the animals utilized in this work, the NIH Core Tetramer Facility at Emory University for manufacturing the NYDNAGTNL tetramer, and the Michigan State University flow cytometry facility for their assistance with the multiple experiments. AA was supported by the Osteopathic Heritage Foundation, as well the MSU Foundation.

\section{Author details}

${ }^{1}$ Genetics Program, Michigan State University, 2240 E Biomedical and Physical Sciences Building, East Lansing, MI 48824, USA. ${ }^{2}$ Department of Pediatrics, Michigan State University, East Fee Hall, East Lansing, Ml 48824, USA. ${ }^{3}$ Department of Microbiology and Molecular Genetics, Michigan State University, 2215, USA Biomedical and Physical Sciences Building, East Lansing, Ml 48824, USA. ${ }^{4}$ College of Osteopathic Medicine, Michigan State University, East Fee Hall, East Lansing, Ml 48824, USA.

Received: 12 March 2012 Accepted: 16 May 2012 Published: 21 June 2012

\section{References}

1. WHO: World Malaria Report 2009. Geneva: World Health Organization; 2008

2. Good MF, Pombo D, Quakyi IA, Riley EM, Houghten RA, Menon A, Alling DW, Berzofsky JA, Miller LH: Human T-cell recognition of the circumsporozoite protein of Plasmodium falciparum: immunodominant T-cell domains map to the polymorphic regions of the molecule. Proc Natl Acad Sci USA 1988, 85:1199-1203.

3. Gordon DM, McGovern TW, Krzych U, Cohen JC, Schneider I, LaChance R, Heppner DG, Yuan G, Hollingdale M, Slaoui M: Safety, immunogenicity, and efficacy of a recombinantly produced Plasmodium falciparum circumsporozoite protein-hepatitis B surface antigen subunit vaccine. J Infect Dis 1995, 171:1576-1585.

4. Zhou Z, Xiao L, Branch OH, Kariuki S, Nahlen BL, Lal AA: Antibody responses to repetitive epitopes of the circumsporozoite protein, liver stage antigen-1, and merozoite surface protein-2 in infants residing in a
Plasmodium falciparum-hyperendemic area of western Kenya. XIII. Asembo Bay Cohort Project. AmJTrop Med Hyg 2002, 66:7-12.

5. Arun Kumar K, Sano G-i, Boscardin S, Nussenzweig RS, Nussenzweig MC, Zavala F, Nussenzweig V: The circumsporozoite protein is an immunodominant protective antigen in irradiated sporozoites. Nature 2006, 444:937-940.

6. Vogels $R$, Zuijdgeest $D$, van Meerendonk M, Companjen A, Gillissen G, Sijtsma J, Melis I, Holterman L, Radosevic K, Goudsmit J, Havenga MJ: High-level expression from two independent expression cassettes in replication-incompetent adenovirus type 35 vector. J Gen Virol 2007, 88:2915-2924

7. Plassmeyer ML, Reiter K, Shimp RL Jr, Kotova S, Smith PD, Hurt DE, House B, Zou X, Zhang Y, Hickman M, Uchime O, Herrera R, Nguyen V, Glen J, Lebowitz J, Jin AJ, Miller LH, MacDonald NJ, Wu Y, Narum DL: Structure of the Plasmodium falciparum circumsporozoite protein, a leading malaria vaccine candidate. J Biol Chem 2009, 284:26951-26963.

8. Coppi A, Natarajan R, Pradel G, Bennett BL, James ER, Roggero MA, Corradin G, Persson C, Tewari R, Sinnis P: The malaria circumsporozoite protein has two functional domains, each with distinct roles as sporozoites journey from mosquito to mammalian host. J Exp Med 2011, 208:341-356.

9. Kappe SH, Buscaglia CA, Nussenzweig V: Plasmodium sporozoite molecular cell biology. Annu Rev Cell Dev Biol 2004, 20:29-59.

10. The RTS SCTP: First results of Phase 3 trial of RTS, S/AS01 malaria vaccine in African children. NEJM 2011, 365:1863-1875.

11. Sun P, Schwenk R, White K, Stoute JA, Cohen J, Ballou WR, Voss G, Kester KE, Heppner DG, Krzych U: Protective immunity induced with malaria vaccine, RTS, S, is linked to Plasmodium falciparum circumsporozoite protein-specific CD4+ and CD8+ T cells producing IFN-\{gamma\}. J Immunol 2003, 171:6961-6967.

12. Kester Kent E, Cummings James F, Ofori-Anyinam $\mathrm{O}$, Ockenhouse Christian F, Krzych U, Moris P, Schwenk R, Nielsen Robin A, Debebe Z, Pinelis E, Juompan L, Williams J, Dowler M, Stewart VA, Wirtz RA, Dubois MC, Lievens M, Cohen J, Ballou WR, Heppner DG Jr, RTS,S Vaccine Evaluation Group: Randomized, double-blind, Phase 2a trial of falciparum malaria vaccines RTS,S/AS01B and RTS,S/AS02A in malarianaive adults: safety, efficacy, and immunologic associates of protection. $J$ Infect Dis 2009, 200:337-346.

13. Kester KE, Cummings JF, Ockenhouse CF, Nielsen R, Hall BT, Gordon DM, Schwenk RJ, Krzych U, Holland CA, Richmond G, Dowler MG, Williams J, Wirtz RA, Tornieporth N, Vigneron L, Delchambre M, Demoitie MA, Ballou WR, Cohen J, Heppner DG Jr, RTS, S Malaria Vaccine Evaluation Group: Phase $2 a$ trial of 0,1 , and 3 month and 0,7 , and 28 day immunization schedules of malaria vaccine RTS, S/AS02 in malaria-naïve adults at the Walter Reed Army Institute of Research. Vaccine 2008, 26(18):2191-2202.

14. Casares S, Brumeanu TD, Richie TL: The RTS, S malaria vaccine. Vaccine 2010, 28(31):4880-4894.

15. Bejon P, Lusingu J, Olotu A, Leach A, Lievens M, Vekemans J, Mshamu S, Lang T, Gould J, Dubois M-C, Demoitié MA, Stallaert JF, Vansadia P, Carter T, Njuguna P, Awuondo KO, Malabeja A, Abdul O, Gesase S, Mturi N, Drakeley CJ, Savarese B, Villafana T, Ballou WR, Cohen J, Riley EM, Lemnge MM, Marsh K, von Seidlein L: Efficacy of RTS, S/AS01E vaccine against malaria in children 5 to 17 months of age. NEJM 2008, 359:2521-2532.

16. Appledorn DM, McBride A, Seregin S, Scott JM, Schuldt N, Kiang A, Godbehere S, Amalfitano A: Complex interactions with several arms of the complement system dictate innate and humoral immunity to adenoviral vectors. Gene Ther 2008, 15:1606-1617.

17. Rollier CS, Reyes-Sandoval A, Cottingham MG, Ewer K, Hill AVS: Viral vectors as vaccine platforms: deployment in sight. Curr Opin Immunol 2011, 23:377-382.

18. Houghton M: Prospects for prophylactic and therapeutic vaccines against the hepatitis C viruses. Immunol Rev 2011, 239:99-108.

19. Ophorst OJ, Radosevic K, Havenga MJ, Pau MG, Holterman L, Berkhout B, Goudsmit J, Tsuji M: Immunogenicity and protection of a recombinant human adenovirus serotype 35 -based malaria vaccine against Plasmodium yoelii in mice. Infect Immun 2006, 74:313-320.

20. Shott JP, McGrath SM, Pau MG, Custers JHV, Ophorst O, Demoitié M-A, Dubois M-C, Komisar J, Cobb M, Kester KE, Dubois P, Cohen J, Goudsmit J, Heppner DG, Stewart VA: Adenovirus 5 and 35 vectors expressing 
Plasmodium falciparum circumsporozoite surface protein elicit potent antigen-specific cellular IFN-[gamma] and antibody responses in mice. Vaccine 2008, 26:2818-2823.

21. McCoy K, Tatsis N, Korioth-Schmitz B, Lasaro MO, Hensley SE, Lin S-W, Li Y, Giles-Davis W, Cun A, Zhou D, Xiang Z, Letvin NL, Ertl HC: Effect of preexisting immunity to adenovirus human serotype 5 antigens on the immune responses of nonhuman primates to vaccine regimens based on human- or chimpanzee-derived adenovirus vectors. J Virol 2007, 81:6594-6604.

22. Abbink $P$, Lemckert AAC, Ewald BA, Lynch DM, Denholtz M, Smits S, Holterman L, Damen I, Vogels R, Thorner AR, O'Brien KL, Carville A, Mansfield KG, Goudsmit J, Havenga MJ, Barouch DH: Comparative seroprevalence and immunogenicity of six rare serotype recombinant adenovirus vaccine vectors from subgroups B and D. J Virol 2007, 81:4654-4663.

23. Barouch DH, Kik SV, Weverling GJ, Dilan R, King SL, Maxfield LF, Clark S, Ng'ang'a D, Brandariz KL, Abbink P, Sinangil F, de Bruyn G, Gray GE, Roux S, Bekker LG, Dilraj A, Kibuuka H, Robb ML, Michael NL, Anzala O, Amornkul PN, Gilmour J, Hural J, Buchbinder SP, Seaman MS, Dolin R, Baden LR, Carville A, Mansfield KG, Pau MG, Goudsmit J: International seroepidemiology of adenovirus serotypes $5,26,35$, and 48 in pediatric and adult populations. Vaccine, . In Press, Corrected Proof.

24. Natuk RJ, Chanda PK, Lubeck MD, Davis AR, Wilhelm J, Hjorth R, Wade MS, Bhat BM, Mizutani S, Lee S: Adenovirus-human immunodeficiency virus (HIV) envelope recombinant vaccines elicit high-titered HIV-neutralizing antibodies in the dog model. Proc Natl Acad Sci USA 1992, 89:7777-7781.

25. Lubeck MD, Natuk RJ, Chengalvala M, Chanda PK, Murthy KK, Murthy S, Mizutani S, Lee SG, Wade MS, Bhat BM: Immunogenicity of recombinant adenovirus-human immunodeficiency virus vaccines in chimpanzees folowing intranasal administration. AIDS Res Hum Retroviruses 1994 10:1443-1449.

26. Stewart VA, McGrath SM, Dubois PM, Pau MG, Mettens P, Shott J, Cobb M, Burge JR, Larson D, Ware LA, Demoitie MA, Weverling GJ, Bayat B, Custers $J$ H, Dubois MC, Cohen J, Goudsmit J, Heppner DG Jr: Priming with an adenovirus 35-circumsporozoite protein (cs) vaccine followed by RTS, S/AS01B boosting significantly improves immunogenicity to Plasmodium falciparum CS compared to that with either malaria vaccine alone. Infect Immun 2007, 75:2283-2290.

27. Rodríguez A, Mintardjo R, Tax D, Gillissen G, Custers J, Pau MG, Klap J, Santra S, Balachandran H, Letvin NL, Goudsmit J, Radosević K: Evaluation of a prime-boost vaccine schedule with distinct adenovirus vectors against malaria in rhesus monkeys. Vaccine 2009, 27:6226-6233.

28. Draper SJ, Biswas S, Spencer AJ, Remarque EJ, Capone S, Naddeo M, Dicks MDJ, Faber BW, de Cassan SC, Folgori A, Nicosia A, Gilbert SC, Hill AV: Enhancing blood-stage malaria subunit vaccine immunogenicity in rhesus macaques by combining adenovirus, poxvirus, and protein-in-adjuvant vaccines. J Immunol 2010, 185:7583-7595.

29. Hilleman MR: Epidemiology of adenovirus respiratory infections in military recruit populations. Ann NY Acad Sci 1957, 67:262-272.

30. Top FH Jr, Dudding BA, Russell PK, Buescher EL: Control of respiratory disease in recruits with type 4 and 7 adenovirus vaccines. Am J Epidemiol 1971, 94:142-146.

31. Jr FHT, Grossman RA, Bartelloni PJ, Segal HE, Burton AD, Russell PK, Buescher EL: Immunization with live types 7 and 4 adenovirus vaccines. I. Safety, infectivity, antigenicity, and potency of adenovirus type 7 vaccine in humans. J Infect Dis 1971, 124:148-154.

32. Jr FHT, Buescher EL, Bancroft WH, Russell PK: Immunization with live types 7 and 4 adenovirus vaccines. II. Antibody response and protective effect against acute respiratory disease due to adenovirus type 7 . $J$ Infect Dis 1971, 124(2):155-160.

33. Schuldt NJ, Aldhamen YA, Appledorn DM, Seregin SS, Kousa Y, Godbehere S, Amalfitano A: Vaccine platforms combining circumsporozoite protein and potent immune modulators, $r E A$ or EAT-2, paradoxically result in opposing immune responses. PLOS One 2011, 6:e24147.

34. Hartman ZC, Appledorn DM, Serra D, Glass O, Mendelson TB, Clay TM, Amalfitano A: replication-attenuated human adenoviral type 4 vectors elicit capsid dependent enhanced innate immune responses that are partially dependent upon interactions with the complement system. Virology 2008, 374:453-467.
35. Appledorn DM, Aldhamen YA, DePas W, Seregin SS, Liu C-JJ, Schuldt N, Quach D, Quiroga D, Godbehere S, Zlatkin I, Kim S, McCormick JJ, Amalfitano A: A new adenovirus based vaccine vector expressing an Eimeria tenella rerived TLR agonist improves cellular immune responses to an antigenic target. PLoS One 2010, 5:e9579.

36. Blum-Tirouvanziam U, Beghdadi-Rais C, Roggero M, Valmori D, Bertholet $\mathrm{S}$, Bron C, Fasel N, Corradin G: Elicitation of specific cytotoxic T cells by immunization with malaria soluble synthetic polypeptides. J Immunol 1994, 153:4134-4141.

37. Perfetto SP, Chattopadhyay PK, Lamoreaux L, Nguyen R, Ambrozak D, Koup RA, Roederer M: Amine reactive dyes: an effective tool to discriminate live and dead cells in polychromatic flow cytometry. $J$ Immunol Meth 2006, 313:199-208.

38. Reyes-Sandoval A, Wyllie DH, Bauza K, Milicic A, Forbes EK, Rollier CS, Hill AVS: CD8+ T effector memory cells protect against liver-stage malaria. J Immunol 2011, 187:1347-1357.

39. Gabitzsch ES, Xu Y, Yoshida LH, Balint J, Amalfitano A, Jones FR: Novel adenovirus type 5 vaccine platform induces cellular immunity against HIV-1 Gag, Pol, Nef despite the presence of Ad5 immunity. Vaccine 2009, 27:6394-6398.

40. Hutnick NA, Carnathan D, Demers K, Makedonas G, Ertl HCJ, Betts MR: Adenovirus-specific human T cells are pervasive, polyfunctional, and cross-reactive. Vaccine 2010, 28:1932-1941.

41. Thorner AR, Lemckert AAC, Goudsmit J, Lynch DM, Ewald BA, Denholtz M, Havenga MJE, Barouch DH: Immunogenicity of heterologous recombinant adenovirus prime-boost vaccine regimens is enhanced by circumventing vector cross-reactivity. J Virol 2006, 80:12009-12016.

doi:10.1186/1475-2875-11-209

Cite this article as: Schuldt et al:: Immunogenicity when utilizing adenovirus serotype 4 and 5 vaccines expressing circumsporozoite protein in naïve and Adenovirus (Ad5) immune mice. Malaria Journal 2012 11:209.

\section{Submit your next manuscript to BioMed Central and take full advantage of:}

- Convenient online submission

- Thorough peer review

- No space constraints or color figure charges

- Immediate publication on acceptance

- Inclusion in PubMed, CAS, Scopus and Google Scholar

- Research which is freely available for redistribution 